\title{
Posočje v sedanjih in nastajajočih slovenskih regijah ter $v$ bližajoči se vključitvi Slovenije v Evropsko skupnost
}

\section{Prispevek $\mathrm{h}$ geografskemu poimenovanju in regionalizaciji Primorske}

\section{Radovan Lipušček}

Gimnazija Tolmin, Dijaška 12 b, 5220 Tolmin, Slovenija e-mail: radovan.lipuscek@guest.arnes.si

\section{Izvleček}

Referat obravnava porečje reke Soče v različnih dosedanjih naravnogeografskih, statističnih, zgodovinskih, političnih, turističnih in drugih regionalizacijah. Ob pojmu severna Primorska se v zadnjem času poskuša uveljaviti še ime Goriška. Avtor predlaga in nato tudi utemeljuje novo ime za sedanjo severno Primorsko oz.statistično regijo Goriška in sicer Slovensko Posočje oz. Posočje.

Ključne besede: regionalizacija, Posočje, Primorska, poimenovanje

\section{Posočje in the Present and newly Founded Slovenia} Regions, as well as in its Uniting in the Europian Union

\section{A Contribution to the Geographic Naming of new Areas in the UE}

\begin{abstract}
The paper deals with the flowing of the Soča river in its different present naturalgeographic, statistical, historical, political, touristic and other regionalizations. With the term northern Primorska there is a strong tendency to use the name Goriška. In order to avoid this the author suggests and as well gives the arguments for the renaming of the present northern Primorska (statistical region) into Slovenian Posočje or Posočje.
\end{abstract}

Key words: regionalisation, Posočje, Primorska, naming 


\section{UVOD}

V zadnjih nekaj letih se veliko govori in piše o regionalizaciji Slovenije tudi $\mathrm{v}$ luči vključevanja v Evropsko skupnost. Ob spremljanju tega dogajanja ugotavljamo, da se na območju Primorske, zlasti pa porečje reke Soče regionalizacija vse bolj zapleta in zamegljuje. V opredelitvi in razdelitvi Primorske in s tem tudi v njeno delitev in poimenovanje na severno in južno (obalno-kraško), se vpleta tudi ime Goriška in Posočje.Pri opredeljevanju te regije posegajo nekateri avtorji v zgodovino, drugi se držijo demografskih ter drugih statističnih območij, tretji pa se opirajo samo na naravne, nacionalne in druge meje.

Opredelitev enotnega poimenovanja regije je zapletala tudi stoletna zahodna meja, ki se je spreminjala skladno $\mathrm{z}$ različnimi državnimi tvorbami $\mathrm{v}$ tem delu Slovenije.

Zaradi teh sprememb in prehodnosti območja je nastala zmeda, ki se danes kaže različni uporabi imen Primorska, zlasti pa imena Posočje. Da bi pripomogel k razrešitvi teh neskladij, bom poskušal utemeljiti predvsem pojem Posočja kot ime regije na stiku naše države z mejo Evropske skupnosti.

Izhajajoč iz osnovnega pojma $\mathrm{v}$ hidrogeografiji, ko opredeljujemo površje s katerega se odmaka voda v neko rečje ali reko s pritoki, s pojmom porečje, sem pričujočo razpravo o Posočju naslonil prav na to teoretično izhodišče.

\section{OBRAVNAVA POSOČJA GEOGRAFSKIH REGIONALIZACIJAH}

Zaradi različnih strokovnih kriterijev pri dosedanjih regionalizacijah je tudi poimenovanje le -teh zelo različno. Pričakovali bi lahko, da bi v geografski literaturi veljala doslednost pri enotnem poimenovanju pokrajin, vendar temu ni tako. Glede na kriterije so si različni avtorji, verjetno tudi zaradi pestrosti naravnih in družbenih razmer na področju Slovenije, ustvarili svojo sliko regij in jih tako tudi poimenovali.

Poglejmo si nekaj primerov, kako se ti opredeljujejo ko prikazujejo območje Posočja.

Anton Melik v svojem temeljnem delu ${ }^{1}$ za proučevanje geografskih značilnosti omenja pojem Posočje na več mestih. V njem piše o alpskem Posočju, o Zgornjem Posočju, ki ga umešča v osrednje Julijske Alpe, "to je tedaj v

\footnotetext{
${ }^{1}$ Melik, A., Slovenija - geografski opis, Opis slovenskih pokrajin, II knjiga, 1.zvezek: Slovenski Alpski svet, Ljubljana, 1954
} 
glavnem zgornje Posočje s Predelsko prevalno pokrajino" in podobno. Izraz "Soška dolina" uporablja samo takrat, ko govori o dolini Soče; za širše območje pa uporablja pojem Zgornje Posočje.

Naravnogeografske členitve Slovenije so najbolj pregledno prikazane v razpravi Draga Kladnika ${ }^{2}$, ki povzema naslednje regionalizacije:

1. Melik - Prirodnogeografska sestava Slovenije (GV, 1946),

2. Melik - Regionalizacija (Regionalnogeografske monografije Slovenije, 1954 - 1960),

3. S. Ilešič - Pokrajinsko - fiziognomske regije Slovenije (Geografski vestnik, 1957/58),

4. I. Gams - Slovenske regije (Geografske značilnosti Slovenije, 1983),

5. I. Gams - Pokrajinsko ekološke regije v Sloveniji (Osnove pokrajinske ekologije, 1986),

6. I. Gams, D.Kladnik, M.Orožen Adamič - Naravnogeografske regije Slovenije (Krajevni leksikon Slovenije, 1986),

7. M. Gabrovec, D.Kladnik, M.Orožen Adamič, M.Pavšek, D.Perko, M. Topole - Slovenske pokrajine (1995 za knjigo Pokrajine v Sloveniji).

V tistem delu, kjer obravnavajo območje severozahodne Slovenije, kamor spada Posočje (zgornje in srednje) je težko na kratko opredeliti enotne meje med posameznimi makro, mezo in mikroregijami. Primerjava med njimi, bi terjala samostojno analizo, ki bi presega okvir te razprave. Iz vsega lahko izluščimo, da uvrščajo avtorji posamezne dele te regije $\mathrm{v}$ skupine s podobnim poimenovanjem.

S to problematiko se ukvarja tudi Drago Perko ${ }^{3}$, ki na zemljevidu Makroregije potegne mejo med alpskim in dinarskim svetom od Kolovrata preko spodnje Idrijce, po Bači, zaobide Šentviško planoto in steče po Idrijci od Reke do Idrije.

Goriška Brda in Vipavsko dolino vključuje v Sredozemski svet.

Na drugem zemljevidu Submakroregije, pa razdeli severozahodno Slovenijo v Alpska visokogorja, Dinarske planote in Sredozemska flišna brda. V nadaljevanju predstavlja tipizacijo za Slovenijo, ki jo je skupina avtorjev ${ }^{4}$ razvila na Geografskem inštitutu Antona Melika ZRC SAZU.

$\mathrm{V}$ večini zgornjih naravnogeografskih regionalizacij je mejna črta med zgornjim in srednjim Posočjem nekje pri Doblarju, med srednjim in južnim Posočjem pa pri Solkanu, s tem, da so Goriška Brda vključena največkrat submediteranski prostor. Pojmi zgornje Posočje, srednje Posočje ali zgornja Soška

\footnotetext{
${ }^{2}$ Kladnik, D., 1996. Naravnogeografske členitve Slovenije, Geografski vestnik, 68, 130 - 156

${ }^{3}$ Perko, D., 1998, Tipizacija in regionalizacija Slovenije, GO, 1/45, 12-17

${ }^{4}$ Dr. M. Gabrovec, D Kladnik, Milan Orožen Adamič, Miha Pavšek, Drago Perko, Maja Topole
} 
dolina in srednja Soška dolina, so redko uporabljeni in še to v smislu obravnavanja delov doline ali porečja do Goriške ravani, naprej pa ne.

Člani Foruma za Goriško so v pripravah na obeleževanje 1000 letnice prve pisne omembe Solkana in Gorice v sodni listini, zbrali različna mnenja v zborniku $^{5}$, ki ga je uredila Inka Štrukelj. Iz zbornika povzemam najpomembnejše.

V prispevku z naslovom Slovenske reginalizacijske dileme v poglavju s podnaslovom Kako regionalizirati zahodno in južno Slovenijo (Primorsko) razpravlja Igor Vrišer $^{6}$ o družbenogeografskih dilemah regionalizacije na zgodovinskem območju imenovanim Primorska. V prvem delu zaključka z zgornjim naslovom, omenja, da je že v času Avstro-Ogrske predstavljala členitev trd oreh. To se vidi tudi iz pregleda upravnih razdelitev te regije v preteklem stoletju. Kot vprašljiva večja administrativna enota se mu sicer zdi Notranjska predvsem zaradi šibkosti Postojne kot središča te regije. "Gravitacijsko neopredeljeno je tudi Idrijsko Cerkljansko območje, ki je deloma usmerjeno proti Novi Gorici, deloma proti Ljubljani."

V prvem delu svoje razprave uporablja pri opredeljevanju regij za predstavitev regionalizacij imena mest. Pri zadnji opredelitvi, ko poimenuje 8 makroregij z regionalnimi imeni pa jih poimenuje takole:

- po porečjih rek: Pomurska, Podravska, Savinjska

- po zgodovinskih pokrajinah: Dolenjska, Gorenjska, Primorska - samo za južno Primorsko

- po legi: Osrednjeslovenska

- po mestih: Goriška

V zaključnem delu teksta o regionalizaciji Primorske doda Primorski in Južni Primorski iz zgornje regionalizacije še imena Obalno-Kraška regija, v oklepaju pa še Primorje in Slovenska Istra.

Dušan Plut v svojem predlogu ${ }^{7}$ regionalizacije Slovenije na makro - in mezo - regije razdeli Primorsko na Severno Primorsko in Južno Primorsko. Severno Primorsko, ki ji dodaja v pomišljaju Goriška in v oklepaju Nova Gorica, razdeli na mezoregije Zgornje Posočje, Idrijsko - Cerkljansko in Goriško. Pri tem velja omeniti uvedbo mezoregije z imenom Zgornje Posočje na območju Soške doline do izliva Idrijce v Sočo. Imena Posočje v nadaljevanju ni uporabljal in tudi ni poimenoval celotnega območja z imenom Posočje, kar bi po moje najbolje ustrezalo poimenovanju te makroregije.

\footnotetext{
${ }^{5}$ Štrukelj, I., Goriška pokrajina, 2000, Nova Gorica, Forum za Goriško

${ }^{6}$ Vrišer, I., 2000, Slovenske regionalizacijske dileme, Goriška pokrajina, Inka Štrukelj, Forum za Goriško, Nova Gorica, 29 - 39.

${ }^{7}$ Plut, D.,2000, Skladnejši regionalni razvoj in regionalizacija Slovenije, isto, 41-60.
} 
Milan Bufon se v obsežni družbeno in politično geografski študiji ${ }^{8}$ ne dotika regionalizacij. Ves tekst je omejen na zgodovinski pregled sprememb meja v tem prostoru. Po uvodnem pregledu meddržavnih meja, se njegova obravnava zoži na obravnavo Goriške v ožjem smislu, tj. na območje sedanje upravne enote Nova Gorica. V zaključnem poglavju - Kratek pogled v bodočnost, pa naj bi "v bodoči "evro-regiji" ob slovensko-italijanski meji, v kateri bi sodelovale vse občine in lokalne uprave, ki sodijo v okvir videmskega sporazuma", sodelovali $\mathrm{v}$ treh teritorialno manjših in zaključenih funkcionalnih enotah:

1. tržaško - istrska-kraška enota

2. goriška - območje nekdanje občine Nova Gorica

3. severna obmejna enota - zajema vse območje občin na tromeji.

$S$ tem vnaša veliko novega $v$ možnosti oblikovanja bodočih regij ob politični meji, katere ob vključitvi Slovenije v Evropsko skupnost ne bo več v obliki kot jo poznamo danes.

Potem, ko podrobno analizira nekatere teoretične razsežnosti regionalizma, pregleda regionalizacijo Slovenije in kritično ovrednoti novo paradigmo razvoja poimenovano "trajnostni razvoj", razmišlja Inka Štrukelj ${ }^{9}$ o razvoju Goriške pokrajine v smislu izreka - misli globalno, deluj lokalno.

Pri tem dosledno uporablja ime "statistična regija 11" poimenovana Goriška. Kljub močnemu in pogosto umetnemu združevanju raznih institucij $\mathrm{v}$ mestu, tudi na račun propadanja sosednjih območij, ugotavlja, da "bi morala svojo razvojno in kulturološko vlogo še okrepiti, še posebej zaradi neposredne bližine Gorice kot središčem Goriške pokrajine ter bodočega večplastnega medregionalnega povezovanja $\mathrm{z}$ italijanskimi obmejnimi področji". To je vsekakor potrebno storiti, če jo primerjamo s sosednjim zamejstvom. Vendar tega ne smemo storiti samo v Novi Gorici, zlasti pa ne na račun slabitve pozicij drugih centralnih krajev ob meji zlasti v Zgornjem Posočju.

Ostali avtorji ${ }^{10} \mathrm{se}$, kljub regijskim ambicijam Nove Gorice kot središča, veliko bolj in stalno ukvarjajo le $\mathrm{z}$ vlogo tega mesta v okvirih nekdanje občine Nova Gorica. Čeprav stalno pišejo o širši regionalni vlogi, ni niti v elaboratu o vlogi regijske razvojne agencije severne Primorske v razvoju regije, nič napisano o tem, kako razviti celotno območje ob meji vse do Bovškega.

\footnotetext{
${ }^{8}$ Bufon, M., 2000, Političnogeografske podlage za oblikovanje Goriške ter njenih družbenih in prostorskih vezi, isto, 61-83.

${ }_{9}^{9}$ Strukelj, I., 2000, Regionalizacija in trajnostni razvoj Goriške pokrajine, isto, 102-118.

${ }^{10}$ Vidmar, C. isto, 119-139, Beltram, T., isto 140-149, Velikonja,R.,150-161 in Konič, M.,
} 
Branko Marušič v svojem pogledu ${ }^{11}$ na nastanek Goriške pokrajine ves čas uporablja za ta zgodovinski pregled nastanek in razvoj Goriške pokrajine v okviru geografskega pojma Posočje. Za ime Gorica pravi, da je "ime dobila po Gorici, naselju, ki je zraslo na eni izmed goric, značilnem površinskem elementu tega območja. Geneza dežele je potemtakem vezana na prostor goriške ravnine in čeprav bi bilo ime dežele prav zaradi tega manj prikladno za celo območje". Povzema po Meliku ${ }^{12}$, ki pravi, da je ime "izredno točna opredelitev njenega nastanka, označba dežele v prirodnem osredju iz katerega je nastala".

Marušič se v svojem pregledu zgodovinskega dogajanja omenja regijo Posočja na stičišču Balkanskega in Apeninskega polotoka. V nadaljevanju tudi piše o skladnosti Goriške pokrajine z geografskim pojmom Posočja in ne pozabi omeniti, da "je bila že leta 1927 obnovljena goriška pokrajina, ki pa je bolj kot nekdanja goriška grofija zajemala Posočje, saj je bila vanjo vključena celotna Vipavska dolina in ves idrijski prostor. Le večji del Krasa, ki pa tako v veliki meri ne sodi v Posočje, je upravno sodil v tržaško pokrajino." Tudi v nadaljevanju piše o jugoslovanskem delu Posočja, v katerem "si moremo zaradi prirodnih danosti, zgodovinskih izkušenj in sedanjih razmer zamisliti le eno pokrajino z enim središčem".

Tukaj misli na Novo Gorico, ki pa ne bi bilo samo središče Goriške pokrajine ampak regije Posočja. To moje dopolnilo se lahko podkrepi tudi z navedbo, ki jo je povzel iz prve številke Goriških srečanj leta 1966, ko pravi "Ozemlje nekdanje zgodovinske dežele, med obema vojnama tudi Goriške pokrajine, se lahko poistoveti z zemljepisnim pojmom Posočje, čeravno je ta pojem, ki pomeni reko Sočo in njene pritoke teritorialno, ozemeljsko obsežnejši od ustaljenega upravnega pojma Goriška. Vsaj zahodni del Posočja ni nikdar (Idrija, Nadiža, Ter) v celoti sodil k Goriški."

Pri oblikovanju novih evropskih obmejnih regij bi to dejstva veljalo zanemariti in ustvariti širšo regijo Posočja.

V nadaljevanju Marušič ugotavlja, da "je bila Goriška upravna celota, naslonjena na Posočje, ki pa je zajemalo širši teritorij. Posočje ni bilo nikdar združeno v neki nižji upravni tvorbi."

Ob koncu pregleda literature, naj ilustriram, kako pomembno je, da sami enotno določimo in poimenujemo posamezne regionalne enote. $Z$ naslednjimi primeri želim opozoriti na dokaj nestrokovne opredelitve regij v sicer poljudnih, vendar zelo poznanih publikacijah kot so turistični vodniki.

\footnotetext{
${ }^{11}$ Marušič, B., 2000, Stalnica ali novost?, isto, 169 - 175

${ }^{12}$ Melik, A., Slovensko Primorje, 1960, 359 - 360
} 
V vodniku iz serije Lonely Planet ${ }^{13}$ je Posočje vključeno v regijo Primorska. Znotraj te regije je uporabljen pojem Soška dolina (The Soča Valey). Primorska je razdeljena še na Centralno Primorsko (Idrija in Cerkno), Kras (Karst Region) in Obalo (The Coast).

Vodnik iz francoske zbirke Petit Fute ${ }^{14}$ Primorsko in z njo Posočje razdeli na severozahodno in jugozahodno. Večino Posočja je umeščeno v severozahodni del Slovenije, v katerem je ob Primorskem delu še Gorenjska. Soška dolina (Vallee de la Soča), je izločena in obravnavana v posebnem poglavju in zajema večino tistih vsebin, ki jih sicer avtorji predstavljajo pod pojmom Primorska. Pojem Primorska pojasnjujejo, da preveden v francoščino pomeni »obalni - litoralni« del in da to ime ne odraža resničnosti, pač pa kontrastnost v pokrajini in lepote zgornje doline Soče (Bovec in Kobarid), centralnega dela (Cerkno in Idrija), ter ostalih. Pojasnjeno pa je, da mediteransko podnebje doseže najskrajnejše dele dolin. Zanimiva je njihova delitev Primorske na:

1. Vallee de la Soča (opis mest Bovec, Kobarid, Tolmin, Nova Gorica)

2. Le pays de Goriška Brda

3. Vallee de Vipava (Vipava, Idrija, Cerkno)

Ob dveh tujih sem si ogledal tudi domač vodnik Slovenija ${ }^{15}$. V njem za Primorsko uporabljajo Goriško in Obalno-Kraško regijo. Območje pa v podrobnostih (po naslovih) obravnava takole:

- pokrajine: Trenta, Svet pod Mangartom, Baška grapa, Goriška Brda, Vipavska dolina,

- mesta: Bovec, Kobarid, Tolmin, Cerkno, Idrija, Nova Gorica (opisuje pokrajino).

\section{REGIJA SLOVENSKO POSOČJE ALI SLOVENSKA POSOŠKA REGIJA}

Iz pregleda literature, ki obravnava regionalizacijo Posočja je razvidno, da uvršča večina avtorjev območje od izliva Idrijce v Sočo navzgor v alpske ali predalpske pokrajine, soško dolino med Mostom na Soči in Solkanom v dinarske ali predalpske pokrajine, vse nižinske pa med primorske.

\footnotetext{
${ }^{13}$ Wilson, N., Fallon, S., Slovenija, Europe in miniature, Lonely Planet, London, 2001

${ }^{14}$ De Suremain, F., Menuit, N., Seror, A., Le gide de Slovenie, Petit Foute Country Guide, 1999, Paris

${ }^{15}$ Chvatal, M., 1998, Slovenija, Založba Turistika, 1998, Kranj
} 
$\mathrm{V}$ kolikor iščemo identiteto tega območja $\mathrm{v}$ zgodovini, je vsak izmed predlaganih izrazov (Goriška, S(s)everna Primorska) neustrezen za poimenovanje celotnega območja, ki ga ta pojem pokriva. Zaradi lažje določitve identitete tega območja predlagam, od zgodovinskih in političnih dogodkov neodvisen, geografski pojem Slovensko Posočje oz. Posočje. Z imenom Posočje ne opredeljujemo le geografsko celoto porečja Soče na slovenski strani, ampak bi, po ukinitvi meja v bodoči razširjeni evropski skupnosti tako lahko poimenovali celotno regijo vključno z območjem porečja Soče do izliva. Tega pa bi lahko poimenovali Italijansko Posočje. Vse pokrajine in upravne enote na eni in drugi strani meje združuje reka, ki prinaša $\mathrm{v}$ življenje prebivalstva ob njej skupne probleme pa tudi koristi.

Regijo in izraz Slovensko Posočje, utemeljujem za najbolj ustreznega iz več vidikov:

1. Identiteta tega območja je s tem imenom natančno določena v Sloveniji in s poimenovanjem celotne regije porečja Soče kot Posočje tudi v Evropi in svetu. S splošnim pojmom severna primorska ali južna primorska lahko povsod po svetu opredeljujejo pokrajine, ki so v podobnem položaju kot sta naši dve "primorski".

2. Opredelitev regije je v Sloveniji enostavnejša in točnejša (že imamo Pomurje in Posavje).

3. Geografsko je območje porečja reke Soče ustrezneje opredeljeno, saj je to območje s katerega se stekajo vse tekoče in talne vode v Sočo in zajema tudi porečja rek Idrijce in Vipave. Deli administrativnih enot na območju teh soških pritokov so že omejene po razvodnicah in ležijo znotraj porečja.

4. Regionalno opredelimo del Slovenije, ki se loči po naravnih in družbenogeografskih značilnostih od obalno-kraške, ki jo označujemo tudi kot $J(j)$ užno-P(p)rimorska.

5. Področje je $\mathrm{v}$ javnosti doslej poimenovano kot Posočje, predvsem zaradi medijske pozornosti ob potresih leta 1976 in $1998 \mathrm{v}$ vendar praviloma napačno tako po obsegu kot vsebini.

6. Zaradi skupnih etnoloških, zgodovinskih (meja, prehodnost, stik kultur) in drugih značilnosti bi bilo ime bolj sprejemljivo tudi za širšo regijo na obeh straneh meje.

7. Ta del Posočja spada v podnebni razvrstitvi v območje submediteranskega podnebja in sicer $\mathrm{v}$ zaledno submediteranski podtip ${ }^{16}$.

8. Proti poimenovanju tega območja za Posočje bi bil lahko ugovor, da bo težko imenovati prebivalce kot Posočane. Vsaj v Sloveniji se je že pojavil

\footnotetext{
${ }^{16}$ Ogrin, D., 1996. Podnebni tipi v Sloveniji, V: Geografski vestnik, 68, ZGD, Ljubljana, 39 - 56
} 
tudi izraz posočnina, ko je bil uveden poseben davek za sanacijo zgradb, ki jih je porušil potres leta 1998 . V znanih slovenskih regijah pa tako ali tako že govorijo o Pomurcih, prebivalcih z območja reke Mure, Posavcih ipd. $\mathrm{O}$ tem naj na tem mestu svoje povedo tudi jezikoslovci.

Kljub pomislekom predlagam, da porečje Soče in s tem tudi Posočje razdelimo v naslednje tri enote:

1. na njen zgornji del - Zgornje Posočje (ali mogoče tudi Alpsko Posočje), ki zajema območje od zgornjih, povirnih območij rek in potokov do ožine pri Mostu na Soči za izlivom reke Idrijce,

2. na srednji del - Srednje Posočje (ali tudi Goriško Posočje), ki ga označuje dolina Soče med izlivom reke Idrijce pri Mostu na Soči in njenim vstopom v Goriško ravan ter

3. na spodnji del porečja Soče - Spodnje Posočje (ali tudi Italijansko Posočje, Laško), med ožino pri Solkanu in izlivom Soče, vključno z Vipavsko dolino.

Ta delitev je na eni strani naslonjena na naravne (klimatske pa tudi reliefne značilnosti), na drugi strani pa na meje upravnih enot.

Tudi s podrobnejšo analizo značilnosti posameznih delov Posočja bi prešli okvir tega referata, zato bom tukaj le naštel po čem se razlikujejo.

\section{Značilnosti Zgornjega Posočja so:}

ledeniška pokrajina, izmenjavanje globinske in bočne erozije, pritoki Soče, velika prodonosnost, visokogorje, sredogorje, tektonika, velike relativne nadmorske višine, značilno planinsko pašništvo, trta samo še v latnikih ob hišah, "adrenalinski" turizem.

\section{Značilnosti Srednjega Posočja so:}

neledeniška pokrajina, večja zastopanost kraških značilnosti, malo pritokov, majhna prodonosnost, antecedentna prodorna dolina Soče, hidroenergetska izraba Soče, vplivi sredozemskega podnebja, način obdelovanja zemlje, trta v brajdah.

\section{Značilnosti Spodnjega Posočja so:}

ravnine, gričevja, izpostavljenost poplavam, reke pogosto spreminjajo svojo strugo, močnejši vplivi sredozemskega podnebja, vinska trta, sadjarstvo, večja zastopanost poljedelstva $\mathrm{v}$ kmetijstvu, večje onesnaženje podtalnice, prometna odprtost, močnejša sklenjena poselitev.

Pri opredeljevanju notranjih meja Posočja, je to enostavneje narediti v slovenskem kot na italijanskem delu. Vsekakor sta zgornja dela območije rek Ter in Nadiže mnogo manjša (krajša) od Soškega. Hidrografska mreža obeh je v 
spodnjem toku dokaj težko določljiva in je potrebno mejo nujno potegniti po razvodnici.

Prav meje v porečjih rek Ter in Nadiže bi v tej regionalizaciji bili potrebni posebne obravnave tako zaradi naravnogeografskih (npr. hidroloških ...), kot tudi družbenogeografskih (robno stičišče treh narodnostnih in jezikovnih skupin - Italijanske, Furlanske in Slovenske) značilnosti.

\section{ZAKLJUČEK}

Ob predvideni bodoči vključitvi Slovenije v Evropo bodo obmejne regije dobile drugačno vlogo kot so jo imele doslej. Zaradi slovenske narodnostne skupnosti v zamejstvu, je prenekatera regionalizacija Slovenije že doslej segla tudi preko meje.

Pojem Posočja v dosedanjem okviru postaja preozek. Razširiti ga bo potrebno na celotno območje porečja Soče, v katerem bo nujna delitev na slovenski in italijanski del. Za Slovenski del bi lahko označili Zgornje in Srednje Posočje, za italijansko pa Spodnje Posočje.

Ob tem se postavlja vprašanje pojma Primorska. Predlagam, da se ta uporablja predvsem za območje, kjer prevladuje obalno submediteranski podtip podnebja.

$\mathrm{V}$ bodoče bo na obmejnih področjih potrebno iskati tiste skupne regionalne značilnosti, ki ne bodo rezultat političnega razdvajanja ampak združevanja. Če postavimo Posočje v širši prostor med Jadranom in Alpami, lahko ugotovimo, da je regija združevanja, da leži v središču med dvema komunikacijama od morja proti srednji Evropi. Prva smer je od Trsta in Benetk mimo Vidma do Beljaka, druga pa poteka od Kopra preko Ljubljane do Beljaka. Leži na stiku romanske in slovanske kulture, na območju, kjer imamo zastopane skoraj vse evropske tipe reliefa, na prostoru, ki mu pravijo Evropa v Miniaturi. Čeprav je sedaj relativno oddaljeno (predvsem zgornji del) od razvitih območij v soseščini, ima veliko priložnost biti v središču dogajanja takrat, ko bo čista voda, prijetno okolje, posebej še varnost, postala posebna vrednota.

\section{Uporabljena literatura:}

Melik,A., Slovenija - geografski opis, Opis slovenskih pokrajin, II knjiga, 1. zvezek: Slovenski Alpski svet, Ljubljana, 1954

Kladnik, D., 1996. Naravnogeografske členitve Slovenije, Geografski vestnik, $68,130-156$ 
Melik - Prirodnogeografska sestava Slovenije (GV, 1946)

Melik - Regionalizacija (Regionalnogeografske monografije Slovenije, 1954 1960)

S Ilešič - Pokrajinsko - fiziognomske regije Slovenije (Geografski vestnik, 1957/58)

I.Gams - Slovenske regije (Geografske značilnosti Slovenije, 1983).

I.Gams - Pokrajinsko ekološke regije v Sloveniji (Osnove pokrajinske ekologije, 1986).

I.Gams, D.Kladnik, M.Orožen Adamič - Naravnogeografske regije Slovenije (Krajevni leksikon Slovenije, 1986).

M.Gabrovec, D.Kladnik, M.Orožen Adamič, M.Pavšek, D.Perko, M.Topole Slovenske pokrajine (1995 za knjigo Pokrajine v Sloveniji).

Štrukelj, I., Goriška pokrajina, Nova Gorica, Forum za Goriško, Nova Gorica, 2000

Vrišer, I., 2000, Slovenske regionalizacijske dileme, Goriška pokrajina, Inka Štrukelj, Forum za Goriško, Nova Gorica, 29 - 39.

Plut, D.,2000, Skladnejši regionalni razvoj in regionalizacija Slovenije, isto, 41-60.

Bufon, M., 2000, Političnogeografske podlage za oblikovanje Goriške ter njenih družbenih in prostorskih vezi, isto, 61-83.

Štrukelj, I., 2000, Regionalizacija in trajnostni razvoj Goriške pokrajine, isto, 102-118.

Vidmar, C. isto, 119-139, Beltram, T., isto 140-149, Velikonja,R.,150-161 in Konič, M.,

Marušič, B., 2000, Stalnica ali novost?, isto, 169 - 175

Chvatal, M., 1998, Slovenija, Založba Turistika, 1998, Kranj

Melik, A., Slovensko Primorje, Ljubljana, 1960, 359 - 360

Wilson, N., Fallon, S., Slovenija, Europe in miniature, Lonely Planet, London, 2001,

De Suremain, F., Menuit, N., Seror, A., Le guide de Slovenie, Petit Foute Country Guide, 1999

Lipušček, R., Regija Posočja ali Posoška regija, rokopis, predavanje v Gemoni (I), 2002

Perko, D., 1998, Tipizacija in regionalizacija Slovenije, Geografski obzornik, $1 / 45,12-17$

Gasparini, A., Projekt za skupni razvoj in medsebojno italijansko - slovensko spoznavanje, Gorska skupnost Nadiških dolin - Špeter Slovenov, Program Interreg II Italija Slovenija, Šempeter ob Nadiži (I) 2000

Ogrin, D.,1996. Podnebni tipi v Sloveniji, V: Geografski vestnik, 68, ZGD, Ljubljana, 39 - 56 


\section{POSOČJE IN THE PRESENT AND NEWLY FOUNDED SLOVENIA REGIONS, AS WELL AS IN ITS UNITING IN THE EUROPIAN UNION}

\section{A contribution to the geographic naming of new areas in the UE}

\section{Summary}

The sociological and political changes have arisen the question for the planners: how should the newly established connections in the areas near the border be named.

The historically settled name of Primorska is geographically clearly defined, because it represents the area up to which the influence of the Mediterranean climate is still present.

This area was all the time after the second world war divided in its northern part and on its southern part (Southern Primorska region).

In geographical literature there was no accuracy in regionalisation and naming of these areas, but Anton Melik in the base work for the study of teh geographical characteristics metions the term Posočje in many places.

In the continuation the author shows different authors and their own regionalization of the Posočje region. At the end it is as well shown the review of the region in tourist guides (Lonely Planet, Le Petit Fute Slovenie, Vodnik Slovenija).

Searching for the identity of that area, we can say that each of suggested terms is not adeqate. That's why I suggest historicaly and politicaly independent geographical term Slovenian POSOČJE This is not the definition only of the Slovenian side, when we become a part of EU the part across the border can be named Italian Posočje.

I argument the region and the term Posočje as the most appropriate from several aspects:

1. The identity of this region is with that name clearly defined in Europe and in the world, too. With a general term northern primorska or southern primorska we can determine the areas which are in the similar situation as our two "primorska" all over the world.

2. The determination of the region in Slovenia is simpler and more accurate (we already have Pomurje and Posavje).

3. Geographically is the area of the Soča basin determined more appropriate, because this is the region from which all the running and underground waters run in the Soča river, it also includes the basin of the Idrijca and the Vipava. 
4. We define the part of Slovenia reigonally. This part is distinguished for its natural and sociogeographical characteristics from the coastal-carst region, which is defined as $\mathrm{S}(\mathrm{s})$ outhern $\mathrm{P}(\mathrm{p})$ rimorska.

5. 5 The region is named as Posočje in public, mainly because of the media during the earthquake in 1976 and 1998, but rather wrongly in context and volume.

6. Because it has a number of common etnological, historical (the border, transition, different cultures..) characteristics the term would be better for a larger region on both sides of the rivers..

7. In the Upper Soča Valley there are also the climate conditions more continental as coastal, what results in the quantity and kind of the rainfall, The so -called submediteranian subtype.

In spite of hesitation I suggest that Posočje should be divided in three units:

1. on its upper part: The Upper Posočje (or Alpine Posočje) which includes the area of upper, parts of the rivers' area, together with the brooks to the narrow of Most na Soči.

2. on its central-(middle) part - The Middle part (or Goriško Posočje), which is lined by the Soča valley from the outfall of the Idrijca at Most na Soči and its entrance to the Goriška plain and

3. on its lower part - The Lower Posočje(or Italian Posočje, Laško), beginning after the river flows to the Goriška plain in Solkan.

\section{The characteristic of the Upper Posočje are:}

glacier-like landscape, the changing deep and side erosion, the presence of the Soča brooks, big gravelling, high mountains, middlands, tectonics, relatively high sea-altitude, pastures, vine is in trellis, adrenalin sports.

\section{The characteristics of the Middle Posočje}

Non-glacier landscape, more of the carst-like characteristics, very few brooks, very little gravelling, the antecendental shape of the Soča valley, the hydroenergetic use of the valley, the mediterranean influence, the way of land cultivating, vine in lattice.

\section{The characteristics of the Lower Posočje}

Flat areas, moors, the flood exposion, rivers change their stream very often, strong influence of the mediterranean climate, vine, orchards, more of the horticulture, the underground water is more polluted, infrastrucure is wider, strongly populated areas.

When defining the inland borders this is much easier in the Slovenian part. It is much more defficult in the western part. The upper area of the ter and Nadiža are much shorter than Soča is. 
The basins of the Ter and Nadiža should desreve a special treatment in this regionalisation, because of the natural and geographical characteristics (specially hydro) and sociogeographic (the connection of three nationality and language groups-Italian, Furlan, and Slovenian group) characteristics.

In the future possible uniting of Slovenia to the EU, the bordering regions will get a different role, because of the Slovenian minority in Italy, where the regionalisation went across the border, too. In the future it will be as well essential to look for the common regional characteristics which will unite and not divide. We can say that in its very heart there is the Posočje region, facing The Roman and Slavic Culture, on the territory where all the European types of the relief are present, sometimes called Europe in its minimum. Although now it is relatively far away from the highly developed regions, it has a great opportunity to apear in the centre of happening, specially when clean water, pleasant environment and security will be a real value. 